\title{
Mineral resource dissipation in life cycle inventories
}

\author{
Antoine Beylot $^{1} \cdot$ Fulvio Ardente $^{1} \cdot$ Serenella Sala $^{1}{ }^{\circledR} \cdot$ Luca Zampori $^{1}$
}

Received: 8 September 2020 / Accepted: 24 January 2021 / Published online: 7 March 2021

(c) The Author(s) 2021

\begin{abstract}
Purpose The assessment of potential environmental impacts associated to mineral resource use in LCA is a highly debated topic. Most current impact assessment methods consider the extraction of resources as the issue of concern, while their dissipation is an emerging concept. This article proposes an approach to account for mineral resource dissipation in life cycle inventories (LCIs), with application to a case study.

Methods The definition of mineral resources is first discussed considering both current main LCA practice and the context of resource dissipation. Secondly, the approach is described: considering a short-term perspective (25 years), any flow of resources to (i) environment, (ii) final waste disposal facilities, and (iii) products-in-use in the technosphere, with the resources not providing any significant function anymore (including due to non-functional recycling), is suggested to be reported as dissipative at the level of unit processes. This approach first requires to map the flows of mineral resources into and out of the unit processes under study ("resource flow analysis"), before identifying the dissipative flows and reporting them in LCI datasets.

Results and discussion The approach is applied to analyze the direct dissipation of mineral resources along the primary production of copper, using Ecoinvent (v3.5) datasets. The production of $1 \mathrm{~kg}$ of copper cathode generates $0.88 \mathrm{~kg}$ of direct dissipative flows of resources (primarily calcium carbonate, copper, and to a lower extent iron), with important contributions of "tailings disposal," "pyrometallurgy," and "mining and concentration." Moreover, this article discusses (i) how the developed approach would change the interpretation of results regarding mineral resources in LCA, (ii) how far some key methodological aspects of this approach (e.g., the temporal perspective) can affect the inventory results (e.g., in the case of the primary production of copper, considering a long-term perspective implies a significant shift in main contributions regarding both unit processes and resource flows), and finally (iii) the issue of new data requirements, in terms of availability and adequacy. Conclusions As demonstrated in the case study, existing LCI datasets and supporting documentation contain at least part of the data and information required to consistently compile the dissipative flows of resources at the unit process level, yet with the need for some complementary data and assessments. This approach may be particularly relevant to better support the development of more resource-efficient techniques or product designs. It is still open how to adapt characterization approaches to account for the impact induced by these resource dissipative flows.
\end{abstract}

Keywords LCA $\cdot$ LCI $\cdot$ Abiotic resources $\cdot$ Metal $\cdot$ Dissipation $\cdot$ Loss

\section{Introduction}

Communicated by Matthias Finkbeiner.

Contribution of the co-authors Antoine Beylot: Conceptualization, Methodology, Investigation, Writing original draft, Writing - review \& editing, Visualization.Fulvio Ardente: Conceptualization, Methodology, Investigation, Writing - original draft, Writing - review \& editing.Serenella Sala: Conceptualization, Writing - review \& editing.Luca Zampori: Conceptualization, Methodology, Investigation, Writing - original draft, Writing - review \& editing, Visualization.

Serenella Sala serenella.sala@ec.europa.eu
In 2011, the International Reference Life Cycle Data System (ILCD) handbook, published by the Joint Research Centre of the European Commission (EC-JRC), provided recommendations on models and characterization factors that should be used for impact assessment in life cycle assessment (LCA; EC-JRC, 2011). This created the basis for the Product and Organization Environmental Footprint

1 Joint Research Centre, European Commission, Via Enrico Fermi 2749, 21027 Ispra, VA, Italy 
(PEF/OEF) recommendations for impact categories and models as per Recommendation 2013/179/EU (EC, 2013). For a PEF/OEF study, 16 impact categories shall be considered, without exclusion and with applying the respective impact category indicators and characterization models (Zampori and Pant 2019). The abiotic depletion potential is recommended to calculate the impacts on resource use, minerals, and metals (ADP, ultimate reserve; Guinée et al. 2002; van Oers et al. 2002). The ADP is based on the concept of resource depletion: the extraction of a resource from the Earth's crust is considered to contribute to this resource depletion (exhaustion of the natural stock). This recommendation is in line with that of the "task force mineral resources" of the United Nations Environment Life Cycle Initiative with respect to the LCA studies which aim at quantifying the relative contribution of a product system to the depletion of mineral resources (Berger et al. 2020).

However, a number of authors have argued that it is not the extraction of materials which is of concern, but rather their dissipative use and disposal (Stewart and Weidema 2005; Vadenbo et al. 2014; Frischknecht and Büsser Knöpfel 2013). Similarly, the dissipation of resources was identified as a promising concept in the PEF/OEF context, whose feasibility for potential implementation has been further discussed (Zampori and Sala 2017; Ardente et al. 2019; Beylot et al. 2020). Moreover, the "task force mineral resources" of the Life Cycle Initiative concludes its recommendations on the use of methods to assess the impact of mineral resource use with calling for the definition of the concept of dissipative resource use and for its integration in future method developments (Berger et al. 2020). To operationalize this concept in LCA, the life cycle inventories (LCIs) need to provide information about dissipative losses or flows and life cycle impact assessment methods need to be adapted or developed to account for the impacts associated with these dissipative flows (Berger et al. 2020). Such developments would enable to go beyond the approaches reported so far in the literature, which in particular discuss the consideration of the quality/functionality of resources in LCA (Stewart and Weidema 2005) and suggest to calculate the dissipative use of resources as the difference between the amounts of resources extracted and recycled in the life cycle of a product or system (Vadenbo et al. 2014; Frischknecht and Büsser Knöpfel 2013). In this context, a number of ongoing projects are developing frameworks to account for resource dissipation and decrease of resource accessibility in LCA (Drielsma and Sochorová 2019; Charpentier Poncelet et al. 2019).

Building on and expanding the feasibility study of Zampori and Sala (2017), this article proposes a new approach to account for dissipative resource flows in the life cycle inventory of a product. Firstly, the definition of mineral resources is discussed considering both current main LCA practice and the specific context of resource dissipation. Then, the approach is detailed and its practical operationalization in LCI databases is discussed. Finally, this approach is applied to the case of the cradle-to-gate production of primary copper, and further discussed considering three main angles: (i) how it would change the interpretation of results regarding mineral resources in LCA, (ii) how far some key methodological aspects of this approach (e.g., the temporal perspective) can affect the inventory results, and finally, (iii) the issue of new data requirements, in terms of availability and adequacy.

\section{Mineral resources, dissipation: defining the concepts in the context of LCA}

\subsection{Mineral resources: current concept in LCA}

The "task force mineral resources" of the Life Cycle Initiative defines "mineral resources" as "chemical elements (e.g., copper), minerals (e.g., gypsum), and aggregates (e.g., sand) as embedded in a natural or anthropogenic stock" (Berger et al. 2020). This definition leaves room for further interpretation in the LCA of a product: the same product system (e.g., copper sheets and aluminum sheets) can be represented by use of different inputs of mineral resource elementary flows from the ecosphere (e.g., respectively copper or chalcopyrite and aluminum or bauxite) at the LCI stage.

\subsection{Abiotic resource dissipation: concept in life-cycle-based studies}

Beylot et al. (2020) describe the status of resource dissipation in the literature of life-cycle-based studies (that is, studies that trace the flows of resources from their extraction to their end-of-life), in particular identifying three main features:

(i) Several authors refer to temporal aspects in their definitions, or as complements to their definitions. However in most cases no temporal aspect is referred to; and when referred to, no specific temporal perspective is provided;

(ii) Most publications account more or less explicitly for dissipative flows to (or within) at least one of the three following compartments: environment, which relates to what is usually called "emissions to the environment" in material flow analysis (MFA) and LCA studies; final waste disposal facilities (in technosphere); and products-in-use (in technosphere), mainly associated with "non- 
functional recycling" (i.e., the incorporation of a material, as a "tramp" or impurity element, in a larger material stream; Beylot et al. 2020);

(iii) In order to quantify dissipative flows in the system under study, most authors define a set of flows that they consider "dissipative," and then calculate the corresponding masses based on different types of data (statistics, process data, assumptions, etc.).

Moreover, building on this literature review, Beylot et al. (2020) provide the following definition:

Dissipative flows of abiotic resources are flows to sinks or stocks that are not accessible to future users due to different constraints. These constraints prevent humans to make use of the function(s) that the resources could have in the technosphere. The distinction between dissipative and nondissipative flows of resources may depend on technological and economic factors, which can change over time.

\subsection{Mineral resources: concept in LCA, adapted to account for dissipation}

The definition of the "task force mineral resources" of the Life Cycle Initiative opens the door to the consideration of mineral resource elementary flows in several diverse ways in life cycle inventories (e.g., in the form of a mineral in the ore, of the elements contained in this mineral or both mineral and contained elements; Berger et al. 2020). Therefore, it is essential to set what is intended as "mineral resource flows" in this study. Firstly, the focus is here set on "dissipative," "natural" resource flows. This is in line with the issue of concern in this study (resource dissipation), and consistent with the area of protection "natural resources" in LCA. This implies that man-made materials (e.g., steel) are not considered as resources in the following, but rather as made of resources (e.g., steel made of iron and several other elements, such as carbon, chromium, and nickel). It is noteworthy that despite "natural," "resources" can be primary (when extracted from the ecosphere) or secondary (when produced from the technosphere; Berger et al. 2020).

Following these considerations, a set of rules is suggested to enable identifying and tracing mineral resources in the life cycle of products, and subsequently to account for their dissipation. It is noteworthy that these rules are necessary to apply the approach described in the following sections to account for resource dissipation in LCA. However, other rules could have been set, compliant with the definition of the "task force mineral resources" and also enabling to account for resource dissipation in LCA.

- Regarding primary mineral resources: (i) "if the mineral or aggregate has a value as such (e.g., gypsum or sand), the mineral is considered the relevant elementary flow" (Berger et al. 2020), that is to say it is the resource; and instead (ii) if the value of a mineral ore is to host elements only, there are different views on what should be considered the resource(s) (as reflected by the definition of the "task force mineral resources"): either the mineral (e.g., chalcopyrite) and/or the totality (or some) of the elements contained therein (e.g., copper). In this study, the target elements in the ore are considered to be the resources (as in the ecoinvent 3 database; Weidema et al. 2013);

- Regarding mineral resources in use in the technosphere, and potentially valuable as secondary resources: as long as the chemical elements, minerals and aggregates hold their original, or a significant, value in the product system under study, they are resources. This enables to account for secondary resources in the product system: not only primary resources can be dissipated, but more generally any chemical element, mineral or aggregate which provides its original or a significant function in a product-in-use;

- Finally, as a basis, the list of mineral resource flows derives from the EF reference package (version 3.0; EC, 2019), considering all minerals classified as "resources from ground".

\section{Method}

\subsection{Rationale: dissipative flows at the unit process level}

The approach consists in reporting the dissipative flows, in mass units, at the unit process level (that is, at the level of the "smallest element considered in the life cycle inventory analysis for which input and output data are quantified"; EC-JRC, 2010). A list of dissipative flows of mineral resources is predefined, in the form: "dissipative flow of mineral resource $x$ to compartment $y$ " (with, e.g., $x=$ copper and $y=$ environment). Dissipative flows can be both elementary flows (exchanges from the technosphere to the ecosphere) and exchanges within the technosphere (from the technosphere to the technosphere). Assuming that $\mathrm{R}$ mineral resources are distinguished in the LCI framework, and $\mathrm{C}$ compartments (e.g., environment, landfills, tailings disposal facilities, etc.), the total number of dissipative flows distinguished equals $\mathrm{R} \times \mathrm{C}$. This approach is in line with most of the studies which have dealt so far with resource dissipation in MFA and SFA, in which a set of dissipative flows is usually predefined before the corresponding masses are calculated based on different types of data (Beylot et al. 2020). Moreover, this 
approach is also consistent with the accounting of other elementary flows in LCI datasets, with a predefined list of flows for which a physical (usually, mass) value should be reported at the unit process level.

\subsection{Temporal perspective considered in this study}

In this article, the temporal perspective considered to assess resource dissipation is set to a rather short-term, that is 25 years. Said in other words, a resource is considered to be dissipated when it is rendered inaccessible to any future user within one generation. It is recalled that, as common practice in LCA (e.g., in the PEF/OEF; Zampori and Pant 2019), the exchanges with the ecosphere/technosphere along the life cycle of a product are integrated over the lifetime of the product under study, and considered to occur at the time the LCA study is conducted. This implies that the 25-year perspective applies to the whole dissipative resource flows over the life cycle of the product under study, considered to occur when the study is carried out.

It is noteworthy that the shorter the temporal perspective, the more reliable the assessment of the resource accessibility to future users. The consideration of longer-term perspectives could fit as well with the general rationale of the approach presented in the previous section (reporting of dissipative resources at the unit process level, considering a pre-defined set of dissipative flows). However, despite potentially adapted to the goal and scope of some LCA studies, long timeframes imply uncertainty on the potential accessibility of resources to future users (related to uncertainty on future potentially economically viable technologies), and are only considered as a sensitivity analysis in this study.

\subsection{Dissipative flows in this temporal perspective}

In a short-term perspective, any flow of resources (i) to the environment (air, water, and soil), (ii) to final waste disposal facilities, and (iii) to products-in-use in the technosphere in which the resource provides a low function, can be reasonably assumed to be "not accessible to future users" (i.e., dissipative). Accordingly, these dissipative flows need to be reported in mass units at the unit process level when constructing LCI datasets (Fig. 1). This approach is in line with the literature of life-cycle based studies which, in the recent years, have increasingly accounted not only for dissipative flows to the environment but also for dissipative flows to final waste disposal facilities and products-in-use in the technosphere (Beylot et al. 2020).

\subsubsection{Dissipation in products-in-use}

It is noteworthy that in the literature, dissipation in productsin-use (in technosphere) mainly corresponds to "nonfunctional recycling" (Beylot et al. 2020). In this article, the concept of dissipation in products-in-use is instead extended to "low-functional recovery" in order to include not only "non-functional recycling" but also other cases of recovery that depart from recycling, for which the recovered material provides such a low function compared to its potential functions (and accordingly, value) that it is not a resource. It is considered that this reduction in functionality is associated with the absence of any technologically feasible and/or economically viable process to recover the original, or any significant, function(s) and associated value of the resource in the temporal perspective considered (that is, 25 years), overall making the resource dissipated.
Fig. 1 Flows at the unit process level: general scheme (from ECJRC; 2010) modified to account for dissipative flows to three main compartments

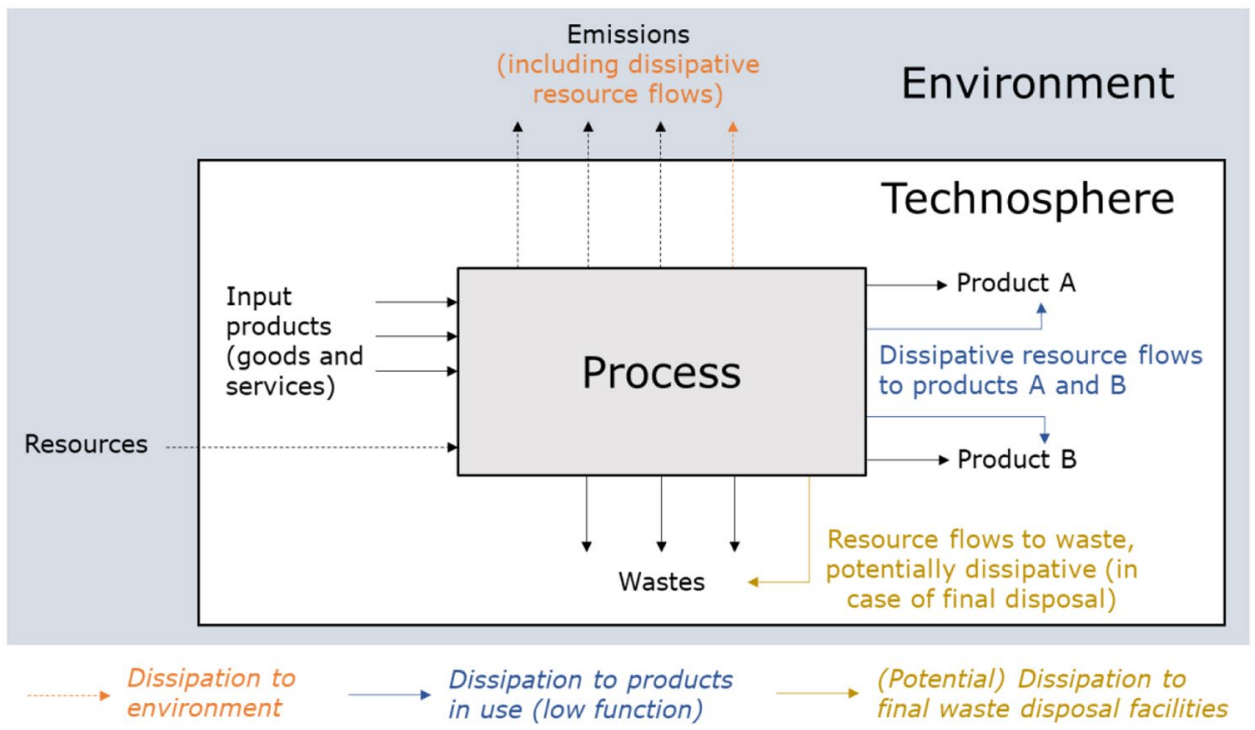


In order to define whether a resource flow to a product-inuse is dissipative or not, LCA practitioners should first assess the potential function of this resource. For example, when slags from a copper smelter are used in construction, they fulfil the function of (and substitute for) natural aggregates. In that case, copper embodied in slags can be considered as recovered with low functionality, with the impossibility to recover the original, or any significant, value of the resource in the temporal perspective considered (absence of any economically viable technology), i.e., it is a dissipative flow (Table 1). On the contrary, quartz sand ending in slags and afterwards used in construction still holds a function equivalent to that of primary quartz sand in its usual application. In that case, quartz sand is considered to hold a "significant function" and is not dissipated (Table 1).

\subsubsection{Dissipation to the environment and to final waste disposal facilities}

Moreover, here as a more generic rule, any flow to the environment and to final waste disposal facilities can be considered dissipated if (and only if) the corresponding substance enters the unit process as a resource (Table 1). However, in some specific cases, such flows of resources to the environment and to final waste disposal facilities may still be accessible to future users in the 25-year timeframe considered (and accordingly, "non-dissipative"). For example, argon, usually produced from the distillation of air, is generally dispersed back to air through its various applications. Such an emission to air can be considered non-dissipative, since the argon is still "accessible to future users" (once back in its original medium, it can be re-extracted with a process similar to the one from which it was initially produced). Moreover, in some specific cases of landfills and tailings disposal facilities, waste may be processed some years later for metal production. This implies that some metals in some final waste disposal facilities may be "accessible to future users" in a 25 -year horizon, depending on a number of parameters including technology capacities and market demand. For example, mineral waste deposited in dumps and tailings ponds at the Penouta Mine in Spain, closed in 1985, have been reprocessed since 2018 (i.e., 33 years after closure) in particular for tin, tantalum, and niobium productions (Blengini et al. 2019). Also, in some cases of landfills, the recovery of secondary materials, through "enhanced landfill mining," may be a complement to actions of environmental remediation or recovery of the land for other uses (Blengini et al. 2019).

\subsubsection{Occupation-in-use is not a form of dissipation}

Contrarily to the flows of resources to the environment, to final waste disposal facilities and to products-in-use in the technosphere with low functionality, occupation-inuse (also called "borrowing-in-use") of resources in the technosphere is not considered as a dissipation. Indeed, by definition of a resource occupation-in-use, the function(s) that the resources could hold in the technosphere is (are) exploited. Yet, it is acknowledged that, despite not being a form of dissipation, occupation-in-use could be considered as potentially affecting the accessibility of the resources for other users.

\subsection{Resource flow analysis to quantify dissipative flows}

The substance flow analysis of resources (called "resource flow analysis" in the following) is the overall concept underlying the suggested approach to account for dissipative flows at the unit process level. It consists in quantifying the flows of resources going through the unit process, entering as resources from ground and resources embodied in products from the technosphere, and coming out either as (i) embodied in the output product, in which

Table 1 Examples of dissipative and non-dissipative flows in the LCI of products

\begin{tabular}{|c|c|c|c|}
\hline & \multicolumn{3}{|l|}{ Flows to } \\
\hline & Environment & Final waste disposal facilities & Products-in-use \\
\hline Dissipative & Copper emitted to air from a copper smelter & $\begin{array}{l}\text { Any metal targeted through an extractive } \\
\text { process-chain, ending in waste to final } \\
\text { disposal (e.g., copper in copper tailings } \\
\text { ponds) }\end{array}$ & $\begin{array}{l}\text { Copper in slags from a copper } \\
\text { smelter, used in construction } \\
\text { (low function) } \\
\text { Any metal non-functionally } \\
\text { recycled (e.g., chromium and } \\
\text { nickel in special steel recycled } \\
\text { in ordinary steel) }\end{array}$ \\
\hline Non-dissipative & $\begin{array}{l}\text { Copper emitted from coal combustion (cop- } \\
\text { per in coal is not considered a resource) } \\
\text { Argon emissions to air }\end{array}$ & $\begin{array}{l}\text { Any metal non-targeted through an extrac- } \\
\text { tive process-chain, ending in waste to final } \\
\text { disposal (e.g. cadmium in copper tailings } \\
\text { ponds) }\end{array}$ & $\begin{array}{l}\text { Quartz sand transferred to slags } \\
\text { through copper smelting, and } \\
\text { used in construction (signifi- } \\
\text { cant function) }\end{array}$ \\
\hline
\end{tabular}


they can either be conserved (that is, holding a significant function in the product) or, by opposition, dissipated (if holding a low function), (ii) directly dissipated as emissions to the environment, and (iii) embodied in a waste for further treatment, and subsequent conservation (i.e., significant function conserved, through e.g. a recycling process in the subsequent life cycle step) or dissipation (e.g., through final disposal in a landfill). Resource flow analysis accordingly enables to identify and quantify all the output dissipative flows of resources at the unit process level, in a consistent way (i.e., in a way that fulfills the mass balance equation). In particular, output mineral flows not entering the unit process as resources shall not be classified as dissipative flows of resources, by definition. This implies for example that regarding emissions to the environment, only emissions of resources (i.e., emissions of substances traced in the resource flow analysis as entering the system as resources from ground or as resources embodied in products) are dissipative flows.

\subsection{Data requirements: potentialities of existing $\mathrm{LCI}$ datasets}

It is expected that existing LCI databases contain at least part of the data and information required to compile the dissipative flows of resources at the unit process level. Two different situations can essentially be distinguished regarding the "dissipative flows" that need to be added to the LCI datasets:

(i) Flows already considered in LCI datasets, but not modelled as "resources dissipated"

This is primarily the case for dissipative flows to the environment, for which the corresponding emissions are reported as elementary flows in existing LCI datasets. However, the following aspects should be considered to account for dissipative flows:

- Only resources can be dissipated (as in Table 1). Accordingly, one needs first to identify the resources inputs to the unit process under study before classifying the corresponding output emissions as dissipative;

- Moreover, some resources are not emitted to the environment "as such." For example, in the mining and metal industry, limestone (primarily calcium carbonate) may be dissipatively used as a reagent and partially emitted to the environment (e.g., as $\mathrm{CO}_{2}$ to air). In such a case, calcium carbonate is the resource dissipated to the environment. More generally, the dissipative resource flow should not be reported as the substance/compound emitted, but rather as the corresponding resource entering the unit process, whether emitted to the environment under the same form or not;

- Finally, the nomenclature should specifically indicate that the corresponding flow is a "dissipative" flow of "resource," i.e., the current approach for reporting emissions to the environment in LCIs should be complemented.

(ii) Flows already considered in the models and supporting documents of existing LCIs

This is the case for waste, products or some emissions (e.g., particulates) which may contain resources potentially dissipated. LCI datasets generally do not provide detailed information on their resource content, but the materials supporting the datasets (e.g., reports or scientific publications) contain a number of elements that could be reinvested with a view to quantifying the amount of resources dissipated (e.g., regarding the elemental composition of waste).

\section{Application to a case study: cradle-to-gate production of copper cathodes}

\subsection{General description}

The approach described in Sect. 3 is applied to analyze the dissipative flows directly generated along the cradle-togate primary production of copper cathodes, considering ecoinvent (v3.5) datasets. This case study aims at exemplifying how existing LCI datasets from major LCI databases could be complemented to account for dissipative resource flows, here in the specific case of an extractive activity for which resource elementary flows are currently inventoried as "extracted from ground."

\subsection{System boundaries}

The functional unit of the study is set as the production of $1 \mathrm{~kg}$ of copper cathode. The system boundaries include (Fig. 2):

- Mining and concentration, which result in the production of copper concentrate (containing around $30 \%$ of copper) from sulfidic copper ore extraction and treatment. This activity additionally generates molybdenite, as a co-product whose subsequent life cycle is considered out of the scope of the system boundaries, and sulfidic tailings (waste). In this case study, tailings are considered to be disposed of in a tailings management facility (heaps or ponds), as common practice in the industry (Classen et al. 2009); 
Fig. 2 System boundaries for the analysis of the cradle-to-gate primary production of copper

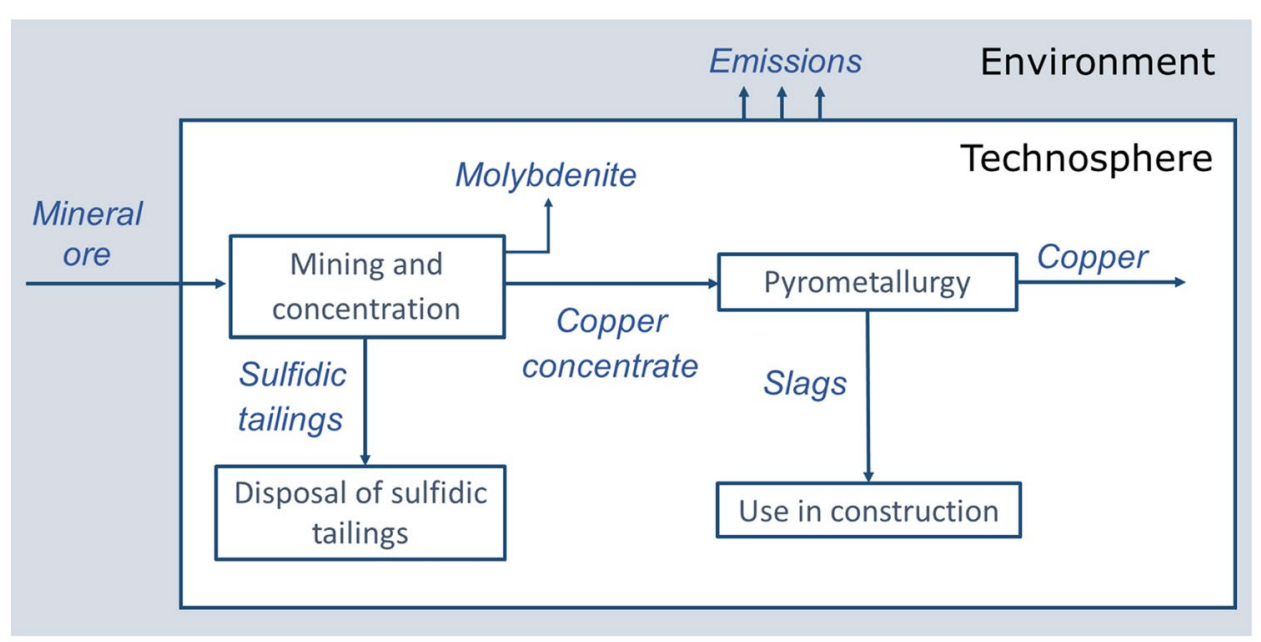

- Pyrometallurgy, resulting in the production of copper cathodes from the treatment of copper concentrate. The process also generates iron silicate slags, considered to be used in construction, as common practice in the industry (Cusano et al. 2017).

\subsection{Life cycle inventory}

This case study mainly builds on the exploitation of two ecoinvent datasets: "copper mine operation, sulfide ore, GLO" and "copper production, primary, GLO," respectively representing the process of copper concentrate production and copper production (from copper concentrate) at a global scale (ecoinvent 2019; Classen et al. 2009). The ecoinvent "undefined system model," corresponding to "the way the datasets are obtained and entered by the data providers," has been considered in the following (ecoinvent 2019). The approach firstly consisted in computing a "resource flow analysis" of the two main activities under study (respectively, mining and concentration, and pyrometallurgy), before deriving an inventory of direct dissipative flows per $\mathrm{kg}$ of output copper cathode.

\subsubsection{Resource flow analysis}

Firstly the mineral resources entering the two activities have been identified and quantified in mass units. The term "resources" is here understood in its large sense, encompassing both primary resources from ground and resources embodied in intermediate products used as inputs to the activities, as defined in Sect. 2.3. It is noteworthy that this step focuses on inputs and outputs of mineral resources, and it does not include inputs of energy carriers. Similarly, the corresponding output flows of mineral resources have been quantified.
In this case study, this resource flow analysis has been performed considering the following hierarchy of data (see Supplementary Information document for a complementary description):

1. Data in inventory datasets, essentially regarding elementary flows of emissions (e.g., copper to air) or resources extracted from ground (e.g. copper and molybdenum from ground). Yet, these data only partially enabled to perform the resource flow analysis of the activities under study. A number of resource flows (embodied in intermediate products used as inputs to the activities, embodied in output products and embodied in waste) cannot be directly drawn from inventory datasets. Complementary data sources have been used, as detailed in the following steps 2 and 3.

2. Background data in the supporting ecoinvent report detailing the inventory compilation, for example regarding the content of copper and molybdenum in copper concentrate and molybdenite (Classen et al. 2009).

3. Hypotheses when no other data considered reliable was available in the ecoinvent database (i.e., either in the datasets or in the supporting documentation). In particular, the masses of resources embodied in reagents in mining, concentration and pyrometallurgy, were derived by combining (i) the mass data present in the ecoinvent dataset and (ii) complementary information regarding the nature of reagents, considering information as in the supporting ecoinvent report (Classen et al. 2009) and additional assumptions. Moreover, the mass of resources transferred to tailings and slags has been calculated by mass balance, considering the difference between the masses of resources as inputs to and as outputs from the activity. This implies in particular assuming that all the resources in the reagents 
(e.g., metals in frothers) are transferred to tailings, and not to the output concentrate, which may not reflect the actual situation in the industry. This could be further explored considering additional plant-specific data beyond the ecoinvent dataset used in this study.

Overall, it is noteworthy that this resource flow analysis is key for several purposes. Firstly, it enables to correctly identify the resources among the output flows. Only the substances that are identified to be resources entering the activities under study can be classified as dissipative flows of resources. Accordingly, for example, emissions of lead, manganese, and mercury to air and water in the activity of mining and concentration are not reported as emissions of resources in the resource flow analysis of the activity. Indeed, these three chemical elements are not entering the activity as resources, neither from ground nor as embodied in intermediate products used as inputs to the activity. In particular, they may originate from trace concentrations in the treated ore, not aimed at being extracted from the process (not "targeted metals") and consequently not considered as resources. Moreover, in some cases, the emission to environment is accompanied by a change in the form of the substance. For example, limestone is used for $\mathrm{pH}$ neutralization in the activity of mining and concentration. It reacts to form emissions (e.g., $\mathrm{CO}_{2}$ ) and waste. In this case, the resource flow analysis enables to identify calcium carbonate as the resource entering the process (considering the EF nomenclature of resources) and subsequently dissipated. Finally, in this specific case study on the primary production of copper, this resource flow analysis is key for the estimation of flows of resources to tailings and slags, calculated by using the mass balance equation. More generally, the use of the mass balance equation in the resource flow analysis enables to ensure the consistent mass balance of resources along the cradleto-gate primary production of copper cathodes.

In the case of the activity of mining and concentration, this resource flow analysis specifically enables to distinguish two main types of resources (Fig. 3): (i) resources targeted by the process of extraction (copper and molybdenum), essentially extracted from ground (e.g., copper mainly transferred to the output copper concentrate), and (ii) resources embodied in products from technosphere, used in the activity, such as reagents and steel for milling, which are not intended to be conserved in the output products (transferred to tailings and environment).

\subsubsection{Derivation of dissipative resource flows}

The inventory of direct dissipative flows along the cradle to gate production of $1 \mathrm{~kg}$ of copper cathodes has been derived from this resource flow analysis (Table 2). This step has mainly involved:

- Distinguishing the dissipative flows (copper and graphite) from the non-dissipative ones (quartz sand), among the flows of resources in slags used in construction (in that case slag is a "product-in-use" in the technosphere; Table 1).

- Considering the resource flows to tailings disposal facilities as dissipative. The recovery of critical and other raw materials from extractive waste is not a widely diffused practice in the European Union yet, despite some notable examples (as e.g., reported in Sect. 3.3.2) which demonstrate the availability of technologies and the exist-
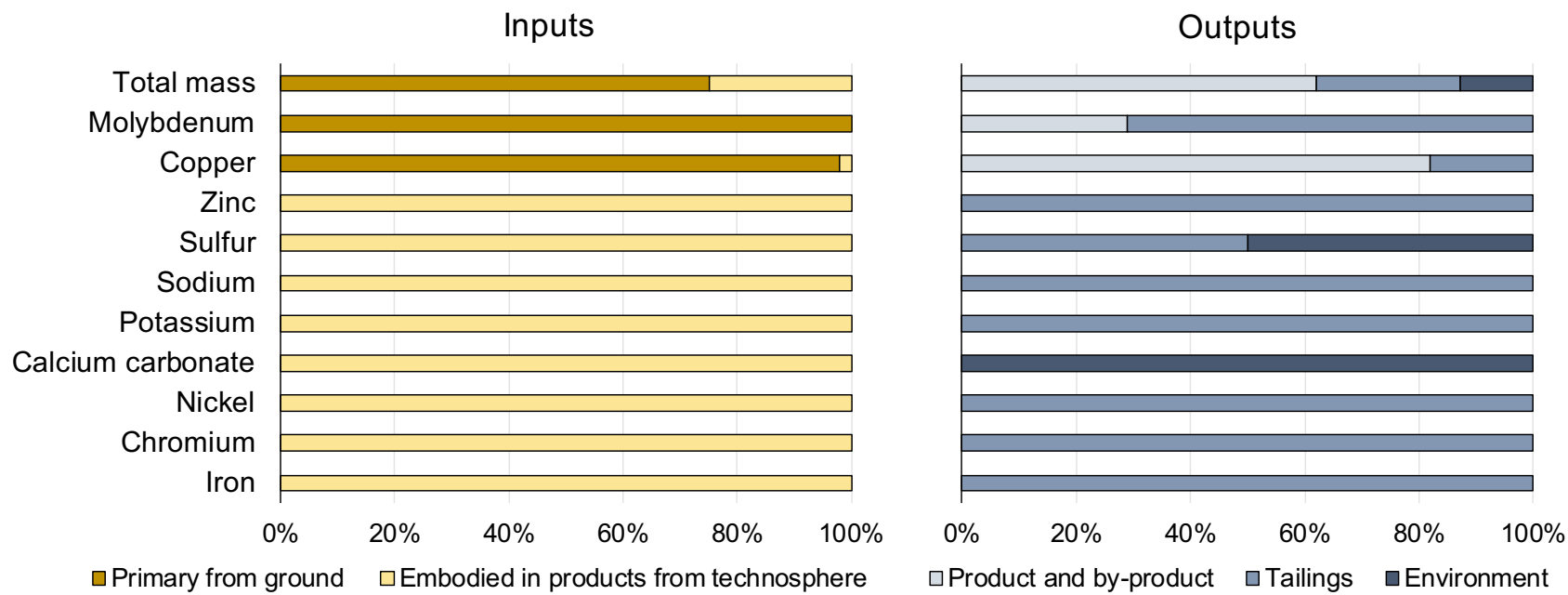

Fig. 3 Mining and concentration of a sulfidic copper ore: resources in input and output flows 
Table 2 Cradle to gate production of $1 \mathrm{~kg}$ of primary copper: inventory of direct dissipative flows of resources (after economic allocation)

\begin{tabular}{|c|c|c|c|c|}
\hline Activity & Type of dissipative resource flow & Amount dissipated & Unit & $\begin{array}{l}\text { Share } \\
\text { of total } \\
\text { mass }\end{array}$ \\
\hline \multirow[t]{8}{*}{ Mining and concentration } & Dissipation to environment & & & \\
\hline & Chromium & $5.78 \mathrm{E}-06$ & $\mathrm{~kg}$ & $0 \%$ \\
\hline & Copper & $4.23 \mathrm{E}-06$ & $\mathrm{~kg}$ & $0 \%$ \\
\hline & Calcium carbonate & $1.98 \mathrm{E}-01$ & $\mathrm{~kg}$ & $22 \%$ \\
\hline & Iron & $5.11 \mathrm{E}-05$ & $\mathrm{~kg}$ & $0 \%$ \\
\hline & Nickel & $8.82 \mathrm{E}-06$ & $\mathrm{~kg}$ & $0 \%$ \\
\hline & Sulfur & $2.84 \mathrm{E}-02$ & $\mathrm{~kg}$ & $3 \%$ \\
\hline & Zinc & $2.41 \mathrm{E}-05$ & $\mathrm{~kg}$ & $0 \%$ \\
\hline \multirow[t]{10}{*}{ Disposal of sulfidic tailings } & Dissipation in tailings disposal facility & & & \\
\hline & Chromium & $1.65 \mathrm{E}-02$ & $\mathrm{~kg}$ & $2 \%$ \\
\hline & Copper & $2.30 \mathrm{E}-01$ & $\mathrm{~kg}$ & $26 \%$ \\
\hline & Iron & $6.79 \mathrm{E}-02$ & $\mathrm{~kg}$ & $8 \%$ \\
\hline & Molybdenum & $1.92 \mathrm{E}-02$ & $\mathrm{~kg}$ & $2 \%$ \\
\hline & Nickel & $7.34 \mathrm{E}-03$ & $\mathrm{~kg}$ & $1 \%$ \\
\hline & Potassium & $5.69 \mathrm{E}-03$ & $\mathrm{~kg}$ & $1 \%$ \\
\hline & Sodium & $2.04 \mathrm{E}-03$ & $\mathrm{~kg}$ & $0 \%$ \\
\hline & Sulfur & $1.42 \mathrm{E}-02$ & $\mathrm{~kg}$ & $2 \%$ \\
\hline & Zinc & $1.15 \mathrm{E}-02$ & $\mathrm{~kg}$ & $1 \%$ \\
\hline \multirow[t]{3}{*}{ Pyrometallurgy } & Dissipation to environment & & & \\
\hline & Copper & $2.75 \mathrm{E}-03$ & $\mathrm{~kg}$ & $0 \%$ \\
\hline & Calcium carbonate & $2.49 \mathrm{E}-01$ & $\mathrm{~kg}$ & $28 \%$ \\
\hline \multirow[t]{3}{*}{ Slags use in construction } & Dissipation in slags used in construction & & & \\
\hline & Copper & $2.99 \mathrm{E}-02$ & $\mathrm{~kg}$ & $3 \%$ \\
\hline & Carbon (graphite) & $1.00 \mathrm{E}-03$ & $\mathrm{~kg}$ & $0 \%$ \\
\hline Total & & $8.84 \mathrm{E}-01$ & $\mathrm{~kg}$ & $100 \%$ \\
\hline
\end{tabular}

ence of a highly innovative sector (Blengini et al. 2019). It is therefore a reasonable assumption to consider that resources in tailings generated and disposed of along the cradle to gate production of $1 \mathrm{~kg}$ of copper cathodes will not be accessible to any future users in a 25-year timeframe, i.e. are dissipated. This assumption is moreover consistent with the modelling of tailings disposal in the ecoinvent database, which does not consider any potential future extraction of their resource content through reprocessing.

- Allocating the dissipative resource flows directly generated by mining and concentration (to environment and tailings disposal facility) respectively to copper concentrate and to molybdenite. Economic allocation has been applied as in Classen et al. (2009). This implies that regarding the co-production of $1 \mathrm{~kg}$ of copper concentrate and $0.0041 \mathrm{~kg}$ of molybdenite, most (99\%) of the dissipative resource flows are allocated to the output copper concentrate, while only a limited share (1\%) is allocated to molybdenite. It is noteworthy that the allocation procedure could have been implemented in different ways, for example considering updated prices of copper concentrate and molybdenite, potentially completed with a physical allocation approach (e.g., considering the allocation of all primary copper resource dissipated to the copper concentrate). More generally, diverse allocation procedures may be applied to dissipative flows of mineral resources in LCI datasets, as is already the case for other elementary flows such as for example mineral resources extracted from the ecosphere (Berger et al. 2020).

\subsubsection{Inventory analysis}

Overall, in order to produce $1 \mathrm{~kg}$ of copper cathode, $0.88 \mathrm{~kg}$ of direct dissipative resource flows are generated in the four unit processes (Table 2). Tailings disposal $(0.37 \mathrm{~kg}$, i.e., representing $42 \%$ of the total mass of resources dissipated; Table 3), pyrometallurgy $(0.25 \mathrm{~kg} ; 29 \%)$, and mining and concentration $(0.23 \mathrm{~kg}, 26 \%)$ all represent important 
Table 3 Share of activities to the total and copper direct dissipative flows of resources along the primary production of copper: comparison of short-term perspective (main approach) and long-term perspective (alternative approach)

\begin{tabular}{llllll}
\hline & Total dissipative flows & & & \multicolumn{2}{l}{ Copper dissipative flows } \\
\cline { 2 - 3 } Activities & $\begin{array}{l}\text { Main approach: short- } \\
\text { term perspective }\end{array}$ & $\begin{array}{l}\text { Alternative approach: long- } \\
\text { term perspective }\end{array}$ & $\begin{array}{l}\text { Main approach: short- } \\
\text { term perspective }\end{array}$ & $\begin{array}{l}\text { Alternative approach: } \\
\text { long-term perspective }\end{array}$ \\
\hline Mining and concentration & $26 \%$ & $47 \%$ & $0 \%$ & $0 \%$ \\
Disposal of sulfidic tailings & $42 \%$ & $1 \%$ & $88 \%$ & $3 \%$ \\
Pyrometallurgy & $29 \%$ & $52 \%$ & & $1 \%$ & $95 \%$ \\
Slags use in construction & $3 \%$ & $0 \%$ & & $11 \%$ & $2 \%$ \\
\hline
\end{tabular}

contributions (in mass terms). Calcium carbonate is the main mineral directly dissipated along the cradle-to-gate production of copper $(0.45 \mathrm{~kg}$, i.e., $51 \%$ of the total mass dissipated; Table 2). Copper also represents a significant contribution (30\% in mass terms), while iron ( $8 \%$ ), sulfur (5\%), molybdenum, and chromium $(2 \%)$ overall represent more limited shares.

Finally, in relation with the above results, one observes that $54 \%$ is dissipated to the environment, $42 \%$ in a disposal facility (disposal of sulfidic tailings), and a much more limited share to a product-in-use (3\% in slags used in construction). However, regarding metals only, dissipation to tailings disposal facilities represents by far the largest share (92\%), while dissipation to the environment only represents a minor share $(1 \%)$. In particular, copper (67\% of the total mass of metals dissipated) is mainly dissipated to tailings disposal facilities (88\%), and to a lower extent in slags used in construction (11\%). Similarly, the metals contained in steel used for milling (iron, chromium, and nickel; $23 \%$ of the total mass of metals dissipated), are essentially dissipated in tailings disposal facilities (Table 2 and Supplementary Information document).

\section{Discussion}

Primarily considering the results of the case study, this section discusses (i) how the developed approach would change the interpretation of results regarding mineral resources in LCA (Sect. 5.1), (ii) how far some key methodological aspects of this approach (e.g., the temporal perspective) can affect the inventory results (Sects. 5.2, 5.3, and 5.4), and finally, (iii) the challenge of potentially incomplete and unbalanced data (Sect. 5.5).

\subsection{From extraction to dissipation: implications on hotspots analysis}

The traditional approach to mineral resources in LCI datasets is to account for the resources extracted from the environment (in particular, from ground). Mineral resource flows are primarily reported with respect to extractive activities. The adoption of the dissipation approach implies focusing not only on the early life cycle stages (associated with raw materials extraction), but also on resource functions in later life cycle stages (in which the resources are dissipated through raw material production and manufacturing, use, recovery or final disposal). This has been partially exemplified in this study considering the cradle-to-gate production of copper, for which the operations of tailings disposal and pyrometallurgy both contribute to relatively important shares of the total mass of resources directly dissipated, whereas they have no direct contribution to resource extraction. The contribution analysis based on resource dissipation rather than extraction implies the identification of different hotspot processes in the cradle-to-gate production of copper, and subsequently potentially different hotspots in terms of stakeholders (different companies) and location (different plants, potentially in different countries).

Moreover this shift in hotspots may be accompanied by a transfer of the resource issue from the background system to the foreground system, where the producer or user of the system under study has decisive influence. For example, regarding calcium carbonate in the cradle-to-gate production of copper, the corresponding concern is identified to be in the foreground in the dissipation approach (dissipative use in concentration and pyrometallurgy). This differs from the extraction approach that would identify the upstream supply chain steps of extraction of calcium carbonate as the hotspot stages.

\subsection{Temporal perspective}

The temporal perspective considered to assess resource dissipation should be defined by LCA practitioners when setting the goal and scope of their study. The approach developed in this article is adapted for users interested in a rather shortterm perspective (i.e., 25 years). If rather considering a longterm perspective (e.g., hundreds of years), emissions to the environment may be assumed to be the only flows of resources "not accessible to future users" (i.e., dissipative). Instead, any 
flow to a final waste disposal facility or recovered with low functionality may be assumed to be, at some point in time, accessible to some future users (i.e., non-dissipative) thanks to e.g. landfill mining and tailings reprocessing.

Regarding the case of primary copper production, this long-term perspective would firstly imply that flows to tailings disposal facilities and slags used in construction are not entirely dissipative. Only the emissions to the environment that they generate may be considered to be dissipative, assuming that instead the rest is "accessible to future users" thanks to potential future reprocessing. In order to assess how far this would affect the results and their interpretation, the emissions induced by tailings disposal are calculated by multiplying the masses of resources in tailings by the transfer coefficients associated with tailings disposal in a 100-yearperspective (as considered in the ecoinvent database to express the share of chemical elements in tailings emitted to the environment through leaching; Doka 2008). Similarly, the transfer coefficients (expressing the share of chemical elements emitted to the environment) for slags disposal in landfills are considered as a proxy to estimate the emissions associated with slags used in construction (Doka 2009).

This long-term perspective implies a significant shift in main contributions at the level of both unit processes and resource inventory flows (see Table 3 which illustrates the different contributions of activities to the direct dissipative flows of resources, when different temporal perspectives are adopted). Pyrometallurgy and mining and concentration are identified as the main process steps (respectively $52 \%$ and $47 \%$ of the total mass dissipated), with calcium carbonate by far the main contributing resource (93\% of the total mass, compared to $51 \%$ in the short-term perspective). On the contrary, tailings disposal and slags use in construction show very limited contributions in mass terms (less than 1\%). Moreover, copper represents less than $1 \%$ of the total mass of resources dissipated, compared to $30 \%$ in the short-term perspective, with pyrometallurgy the main process step (95\% of the total copper dissipated compared to $1 \%$ in the short-term perspective; Table 3). Indeed, in the shortterm perspective, a relatively large amount of copper is considered to be dissipated in tailings final disposal facilities $\left(2.30 \times 10^{-1} \mathrm{~kg}\right)$ compared to the amount dissipated in the step of pyrometallurgy $\left(2.75 \times 10^{-3} \mathrm{~kg}\right.$ as direct emissions to the environment along the process operations; Table 2). Instead, in the long-term perspective, copper in tailings disposal facilities are considered to be accessible to some future users (i.e., non-dissipative) at some point in time thanks to tailings reprocessing, except the share emitted to the environment over time $\left(7.7 \times 10^{-5} \mathrm{~kg}\right)$. In the meantime, the amount of copper considered to be dissipated in the step of pyrometallurgy is identical both in the short-term and in the long-term perspectives $\left(2.75 \times 10^{-3} \mathrm{~kg}\right)$.

\subsection{Compartments of dissipation}

The proposed approach distinguishes three main compartments of dissipation (environment, final waste disposal facilities and products-in-use in the technosphere in which the resource provides a low function), implying the distinction of $3 \times \mathrm{R}$ dissipative flows (considering that $\mathrm{R}$ mineral resources are distinguished in the LCI framework). These three compartments can be subdivided further into $\mathrm{S}$ sub-compartments, as for example additionally considered in the application to the case study ("tailings in disposal facility" and "slags used in construction" considered as sub-compartments respectively of "final waste disposal facilities" and of "products-in-use in the technosphere").

As a complement, further disaggregation could for example consist in differentiating several types of landfills as a function of the waste categories disposed of, several types of tailings to disposal facilities as a function of the ore mined, etc. This differentiation between sub-compartments in particular appears of interest (i) in an accounting perspective (when building the inventory, it helps to generate a comprehensive set of dissipative flows), and (ii) in the results interpretation step, offering possibilities to analyze the contributions of each compartment of dissipation regarding the impacts associated with resource dissipation, therefore helping to prioritize actions to limit resource dissipation in the life cycle of the product under study. The need to differentiate between specific additional sub-compartments of dissipation (and by opposition, of non-dissipation) may be additionally identified in future developments of the approach, for example through the potential introduction of additional criteria to quantify the actual dissipation of resources in each compartment (e.g., concentration of metals).

The coupling of resources to compartments (or subcompartments) may in particular depend on the temporal perspective considered. For example, in the short-term perspective in this study, three compartments and subcompartments are distinguished: environment, tailings in disposal facility and slags used in construction (Table 2). Instead, in the long-term perspective, only the environment may be considered a compartment of dissipation (see Sect. 5.2). Moreover, it is noteworthy that the distinction of additional sub-compartments may be accompanied by the distinction between some resources dissipated and some not, as a function of the sub-compartment; i.e. with a total number of dissipative flows inferior to $\mathrm{R}$ (resources) $\mathrm{X} \mathrm{S}$ (sub-compartments). This may particularly be the case for temporal perspectives in-between short- and long-terms, 
which may require including considerations on potential future reprocessing of tailings or future landfill mining for some mineral resources (see Sect. 3.3.2).

\subsection{Low-functional recovery}

The developed approach does not provide any clear-cut rule regarding what should be considered resources with "low functionality," as opposed to resources with "significant" value in products-in-use. Accordingly, despite applicable in the case study (Table 1 and Table 2), the classification as dissipative in products-in-use may be less straightforward regarding other applications. Additional developments and further research are therefore necessary to define and account more precisely for the actual low-functional recovery and subsequent dissipation of resources in products-in-use, e.g., considering criteria and thresholds. These developments may build on existing approaches implemented in LCA, which consider the quality of materials to account for the benefits of recycling (e.g., in the Circular Footprint Formula of the PEF/OEF; Zampori and Pant 2019).

\section{5 (Un)balanced resource flows}

In the case study, the resource flows transferred to the tailings have been calculated by difference, using the mass balance equation and available data on inputs and outputs. Another option would have been to use the data supporting the ecoinvent dataset relative to tailings management in a disposal facility (provided by Doka 2008), which consider a global average sulfidic tailings composition, based on literature data mainly from copper, zinc, lead, nickel and molybdenum mining sites (Doka 2008). However, considering these data would have implied inconsistent mass balances for the resources under study, e.g., regarding copper for which the mass in tailings would have been 2.5 times lower than the value obtained by mass balance. Indeed, whereas the mass balance calculation implemented in this study considers the copper content in the ore and the process efficiency (and corresponding transfer to tailings) as modelled in the ecoinvent dataset "copper mine operation, sulfide ore, GLO," the ecoinvent dataset relative to tailings management on the contrary considers an average tailings composition, generated by the extraction and processing of diverse ores (not only copper ores but also other metallic ores, with potentially very diverse contents in copper).

Generally, it is expected that resource flows are well traced in the mining and metal activities. Metallurgical accounting is a common practice to quantify the performances of production plants, in particular regarding metal recovery and losses which drive the economic balance of the plant and for which the use of data reconciliation method and tools appears as best practice (e.g., Brochot and Durance 2012). The implementation of the dissipation concept in LCIs could take advantage of such existing "resource flow analyses." On the contrary, in many other types of activities, such analysis of flows may be lacking. In such cases, the whole set of available data may be used, and (i) if complete, being improved by reconciliation techniques, and (ii) if incomplete, being complemented by using the mass balance equation, as done in the above case study regarding the copper tailings and slags compositions.

\section{Conclusions and perspectives}

This article proposes an approach to account for mineral resource dissipation along the life cycle of a product. Considering a short-term perspective (25 years), any flow of resources to (i) environment, (ii) final waste disposal facilities, and (iii) products-in-use in the technosphere (with low functionality) is suggested to be reported as dissipative at the level of unit processes. This approach provides a different perspective to the resource issue as classically considered in LCA, in which primary resource extraction is usually under focus. Accounting for resource dissipation in LCIs implies partly transferring the resource focus from the extraction stage to stages later in the life cycle (resource dissipation through raw material production and manufacturing, use, recovery or final disposal). Therefore, this approach appears well adapted to identify potential improvements on life cycle stages for which the producer or user of the system under study has decisive influence. It may accordingly be particularly relevant to better support the development of more resource-efficient techniques or product designs. However, the transfer of the resource focus from the extraction stage to stages later in the life cycle has only been partially explored in this cradle-togate case study. The accounting of resources dissipated rather than resources extracted implies transferring the focus from copper mining and concentration to the disposal of tailings, pyrometallurgy, and subsequent slags management. This calls for additional case studies considering the full life cycle of products and systems, in order to explore further resource dissipation in the use, recovery, and final disposal phases of these products and systems.

Such a significant change in the perspective adopted to approach the issue of mineral resources in LCA would necessarily imply significant changes in LCI datasets, mainly in terms of a significant adjunction of new flows. As demonstrated in this study in the case of ecoinvent data for copper production, it is expected that existing LCI datasets and supporting documentation contain at least part of the data and information required to compile the dissipative flows of resources at the unit process level. Moreover, the developed approach could also take 
advantage of current practices in some industries, in which resource flow analysis is a common practice with respect to process control, development, and optimization, from lab to industrial scales. In parallel, novel aspects such as a precise definition and accounting of low-functional recovery will also require further research.

Finally, such a significant change in the perspective regarding the resource issue in LCA also implies the need for an adapted impact assessment method, in order to account for the impact actually induced by the dissipative flows of resources. Such method development appears a major requirement for any potential future routine implementation of the concept of resource dissipation in LCA.

Supplementary information The online version contains supplementary material available at https://doi.org/10.1007/s11367-021-01875-4.

Funding The present study has been financially supported by the Directorate General for the Environment (DG ENV) of the European Commission in the context of two Administrative Arrangements between DG ENV and the European Commission Joint Research Centre: Environmental Footprint and Material Efficiency (EFME 3) 33909 - 07.0201/2015/704456/SER/ENV.AI and Technical support for the Environmental Footprint and the Life Cycle Data Network (EF4) DG ENV N ${ }^{\circ} 070201 / 2019 / 811467 / A A / E N V . B .1$

Open Access This article is licensed under a Creative Commons Attribution 4.0 International License, which permits use, sharing, adaptation, distribution and reproduction in any medium or format, as long as you give appropriate credit to the original author(s) and the source, provide a link to the Creative Commons licence, and indicate if changes were made. The images or other third party material in this article are included in the article's Creative Commons licence, unless indicated otherwise in a credit line to the material. If material is not included in the article's Creative Commons licence and your intended use is not permitted by statutory regulation or exceeds the permitted use, you will need to obtain permission directly from the copyright holder. To view a copy of this licence, visit http://creativecommons.org/licenses/by/4.0/.

\section{References}

Ardente F, Beylot A, Zampori L (2019) Towards the accounting of resource dissipation in LCA. XIII Conference of Rete Italiana LCA, Rome, 14-15 June 2019.

Berger M, Sonderegger T, Alvarenga R, Bach V, Cimprich A, Dewulf J, Frischknecht R, Guinée J, Helbig C, Huppertz T, Jolliet O, Motoshita M, Northey S, Peña AC, Rugani B, Sahnoune A, Schrijvers D, Schulze R, Sonnemann G, Valero A, Weidema BP, Young SB (2020) Mineral resources in Life Cycle Impact Assessment - part II: recommendations on application-dependent use of existing methods and on future method development needs. Int J Life Cycle Ass 25:798-813. https://doi.org/10.1007/s11367020-01737-5

Beylot A, Ardente F, Sala S, Zampori L (2020) Accounting for the dissipation of abiotic resources in LCA: status, key challenges and potential way forward. Resour Conserv Recy 157:104748. https:// doi.org/10.1016/j.resconrec.2020.104748

Blengini GA, Mathieux F, Mancini L, Nyberg M, Viegas HM (Editors); Salminen J, Garbarino E, Orveillon G, Saveyn H, Mateos Aquilino V, Llorens González T, García Polonio F, Horckmans
L, D’Hugues P, Balomenos E, Dino G, de la Feld M, Mádai F, Földessy J, Mucsi G, Gombkötő I, Calleja I (2019) Recovery of critical and other raw materials from mining waste and landfills: State of play on existing practices, EUR 29744 EN, Publications Office of the European Union, Luxembourg, ISBN 978-92-7608568-3, https://doi.org/10.2760/600775

Brochot S, Durance MV (2012) A New Approach to Metallurgical Accounting. 11th Mill Operators' conference 2012 / Hobart, TAS, 29-31 October 2012.

Charpentier Poncelet A, Loubet P, Laratte B, Muller S, Villeneuve J, Sonnemann G (2019) A necessary step forward for proper non-energetic abiotic resource use consideration in life cycle assessment: the functional dissipation approach using dynamic material flow analysis data. Resour Conserv Recy 151:104449. https://doi.org/10.1016/j.resconrec.2019.104449

Classen M, Althaus HJ, Blaser S, Tuchschmid M, Jungbluth N, Doka G, Faist Emmenegger M, Scharnhorst W (2009) Life cycle inventories of metals. Final report ecoinvent data v2.1 No.10. EMPA Dübendorf, Swiss Centre for Life Cycle Inventories, Dübendorf, $\mathrm{CH}$.

Cusano G, Rodrigo Gonzalo M, Farrell F, Remus R, Roudier S, Delgado Sancho L (2017) Best available techniques (BAT) reference document for the main non-ferrous metals industries, EUR $28648 \mathrm{EN}$, https://doi.org/10.2760/8224

Doka G (2008) Life cycle inventory data of mining waste: emissions from sulfidic tailings disposal. Gabor Doka Zürich. April 2008. Available at: https://www.doka.ch/SulfidicTailingsDisposalDoka. pdf Last visit: November 2020

Doka G (2009) Life cycle inventories of waste treatment services. Ecoinvent report No 13. Swiss Centre for Life Cycle Inventories, Dübendorf, 2009.

Drielsma J, Sochorová V (2019) SUstainable management of PRIMary raw materials through a better approach in Life Cycle Sustainability Assessment (SUPRIM). Newsletter, May 2019. Available at: http://www.euromines.org/files/suprim-newsletter_ 210x297mm_e_final_0.pdf Last visit: November 2019

EC (European Commission) (2013) Commission Recommendation of 9 April 2013 on the use of common methods to measure and communicate the life cycle environmental performance of products and organisations. 2013/179/EU

EC (European Commission) (2019) Environmental Footprint reference package 3.0 (EF 3.0). Available at: https://eplca.jrc.ec.europa.eu/ LCDN/developerEF.xhtml. Last visit October 2020.

EC-JRC (European Commission - Joint Research Center), 2010. International Reference Life Cycle Data System (ILCD) Handbook - General guide for Life Cycle Assessment - Detailed guidance. First edition (2010) EUR 24708 EN. Publications Office of the European Union, Luxembourg

EC-JRC (European Commission - Joint Research Center) (2011) International Reference Life Cycle Data System (ILCD) Handbook- Recommendations for Life Cycle Impact Assessment in the European context. EUR 24571 EN. Luxemburg. Publications Office of the European Union

ecoinvent. 2019. The ecoinvent Database. Available at: https://www. ecoinvent.org/home.html (Accessed November 2019)

Frischknecht R, Büsser Knöpfel S (2013) Swiss Eco-Factors 2013 according to the Ecological Scarcity Method. Methodological fundamentals and their application in Switzerland. Environmental studies no. 1330. Federal Office for the Environment, Bern, p 254

Guinée JB, Gorée M, Heijungs R, Huppes G, Kleijn R, de Koning A, van Oers L, Wegener Sleeswijk A, Suh S, Udo de Haes HA et al (2002) Handbook on life cycle assessment: operational guide to the ISO standards. Kluwer Academic Publisher, Dordrecht, The Netherlands, p 2002

Stewart M, Weidema B (2005) A consistent framework for assessing the impacts from resource use. A focus on resource functionality. Int J Life Cycle Ass 10,4, 240 - 247. 
Vadenbo C, Rørbech J, Haupt M, Frischknecht R (2014) Abiotic resources: new impact assessment approaches in view of resource efficiency and resource criticality - 55th Discussion Forum on Life Cycle Assessment. Zurich, Switzerland, Int J Life Cycle Ass 19(10):1686

Van Oers L, de Koning A, Guinée JB, Huppes G (2002) Abiotic Resource Depletion in LCA. Road and Hydraulic Engineering Institute, Ministry of Transport and Water, Amsterdam

Weidema BP, Bauer C, Hischier R, Mutel C, Nemecek T, Reinhard J, Vadenbo CO, Wernet G (2013) Overview and methodology. Data quality guideline for the ecoinvent database version 3 . Ecoinvent Report 1(v3). St. Gallen: The ecoinvent Centre
Zampori L, Sala S (2017) Feasibility study to implement resource dissipation in LCA, EUR 28994 EN. Publications Office of the European Union, Luxembourg. https://doi.org/10.2760/869503

Zampori L, Pant R (2019) Suggestions for updating the Product Environmental Footprint (PEF) method, EUR 29682 EN. Publications Office of the European Union, Luxembourg. https:// doi.org/10.2760/424613

Publisher's Note Springer Nature remains neutral with regard to jurisdictional claims in published maps and institutional affiliations. 